\title{
PENGARUH KUALITAS PRODUK DAN KUALITAS PELAYANAN TERHADAP TINGKAT KEPUASAN DAN NIATAN LOYALITAS PADA PEMONDOKAN MAHASISWA PERGURUAN TINGGI $X$
}

\author{
Howard S. Giam ${ }^{1)}$, Fahrul Riza ${ }^{2)}$ \\ ${ }^{1}$ Fakultas Ilmu Sosial dan Humaniora, Universitas Bunda Mulia \\ email: howard_giam@bundamulia.ac.id \\ ${ }^{2}$ Fakultas Ilmu Sosial dan Humaniora, Universitas Bunda Mulia \\ email: friza@bundamulia.ac.id
}

\begin{abstract}
Homestay or dormitory is one of primary needs student who studied far from their home town. This demand for home stay have been responding by residents around the campus by promote an empty space or room at their home to be rent. As one of strategy to expand the quality of service and generate a new income channel, campus or university have been also providing homestay for their student which used to call dormitory and it's managed by professional management building. A tight competitiveness in this business have made the management building need to explore what factors will cause increase satisfaction and loyalty from dormitory's tenant. This paper investigated impact of quality product and quality service to loyalty intention with satisfaction as a moderating variable among 102 tenants of student dormitory from University $X$. The findings was product quality wasn't affect the satisfaction and loyalty intention, meanwhile service quality was significant at $\alpha 1 \%$. Implication of these findings management building dormitory from University $X$ must improve their service quality to attain loyality from tenants.
\end{abstract}

Keywords: Service Quality, Product Quality, Loyalty Intention, Satisfaction

\begin{abstract}
Abstrak
Pemondokan merupakan kebutuhan primer bagi para mahasiswa dan juga mahasiswi (selanjutnya ditulis mahasiswa) yang menuntut ilmu jauh dari tempat tinggal asalnya. Penelitian ini menguji bagaimana pengaruh kualitas produk dan kualitas layanan terhadap tingkat kepuasan dan niatan loyalitas (loyalty intention) para penyewa kamar pemondokan mahasiswa di Perguruan Tinggi $X$. Penelitian ini menggunakan metode kuantitatif dengan sampel sebanyak 102 mahasiswa penyewa pemondokan Perguruan Tinggi X. Hasil uji regresi menunjukan variabel kualitas layanan berpengaruh signifikan terhadap tingkat kepuasan penyewa. Sementara untuk variabel kualitas produk, tidak memiliki pengaruh yang signifikan terhadap tingkat kepuasan penyewa. Penelitian ini baru meninjau kepuasan secara umum dengan menggunakan kualitas produk dan kualitas jasa. Penelitian selanjutnya diharapkan dapat menambah variabel-variabel yang diduga berpengaruh terhadap tingkat kepuasan penyewa dengan melibatkan responden yang lebih banyak dan beragam.
\end{abstract}

Kata Kunci: Kualitas Layanan, Kualitas Produk, Niatan untuk Loyal, Kepuasan 


\section{PENDAHULUAN}

Pemondokan

kebutuhan primer bagi para mahasiswa dan juga mahasiswi (selanjutnya ditulis mahasiswa) yang menuntut ilmu jauh dari tempat tinggal asalnya. Pemondokan tersebut akan menjadi tempat tinggal mereka untuk beberapa tahun sampai dengan mereka menamatkan studinya di perguruan tinggi. Di pemondokan tersebut, mereka akan memulai aktivitasnya dan beradaptasi dengan lingkungannya. Di pemondokan juga para orang tua sesekali waktu akan menengok keadaan anaknya.

Pada lokasi sekitar kampus maupun perkantoran, beragam pemondokan tersedia. Mulai dari yang sangat sederhana dengan lantai semen dan dinding pembatas dari kayu dan berlokasi di jalanjalan sempit, sampai dengan pemondokan mewah di jalan utama dengan berbagai fasilitas seperti Air Conditioner, Wi-Fi, kamar mandi pribadi dan garasi kendaraan roda empat. Dimulai dari yang bertarif sewa hanya ratusan ribu perbulan sampai dengan jutaan ber bulan. Semuanya tergantung pada kemampuan anggaran calon penghuni pemondokan dan kenyamanan yang ingin didapatnya. Meningkatnya jumlah mahasiswa dari luar kota pada Perguruan Tinggi $X$, membuat Perguruan Tinggi $X$ perlu menyediakan fasilitas pemondokan untuk mahasiswa sesuai standar kelayakan, agar mahasiswa merasa aman dan nyaman selama menuntut ilmu selama kuliah.

Untuk memenuhi kebutuhan tersebut Perguruan Tinggi $\mathrm{X}$ mendirikan pemondokan mahasiswa, fasilitas berbayar khusus bagi mahasiswa perguruan tinggi $\mathrm{X}$ yang dilengkapi dengan pendingin ruangan, jasa cuci pakaian, sistem keamanan 24 jam, kantin, Wi-Fi dan aula ruangan belajar. Perguruan Tinggi $\mathrm{X}$ ingin memberikan tingkat kenyamanan dan kemudahan kepada mahasiswa. Sehingga para orang tua pun akan merasa tenang menitipkan anaknya di pemondokan yang dikelola secara profesional. 
Dari aspek pemasaran, para mahasiswa yang tinggal di pemondokan adalah pelanggan. Pelanggan harus dijaga dan dipertahankan kepuasannya agar loyal dalam mengguankan produk atau jasa (Irawan, 2008). Seberapa besar tingkat kepuasan yang dirasakan oleh para pelanggan sangat ditentukan oleh bermacam faktor diantaranya kualitas produk, kualitas layanan, emosi, harga dan kemudahan yang dirasakan (Irawan, 2008).

Pengelola pemondokan melihat adanya gejala penurunan tingkat hunian, yang berakibat kapasitas ruang kamar tidak terisi secara penuh. Guna mengantisipasi lebih menurunnya tingkat hunian membuat manajemen harus mengambil tindakan yang tepat dan melakukan penelitian terkait kepuasan dan loyalitas para penyewa. Penelitian ini menguji bagaimana pengaruh kualitas produk dan kualitas layanan terhadap tingkat kepuasan dan niatan loyalitas (loyalty intention) para penyewa kamar pemondokan mahasiswa di Perguruan Tinggi X.

\section{RERANGKA KONSEPTUAL DAN HIPOTESIS}

\section{Kepuasan Pelanggan}

Irawan (2008) berpendapat kepuasan pelanggan adalah hasil akumulasi perasaan dari konsumen atau pelanggan dalam menggunakan produk dan jasa. Pelanggan puas jika setelah membeli dan menggunakan suatu produk, ternyata kualitasnya baik. Oleh karenanya, setiap transaksi atau pengalaman baru, akan memberikan pengaruh terhadap kepuasan pelanggan. Pelanggan yang puas akan mudah menjadi loyal terhadap produsen atau penyedia jasa. Bahkan, akan berbagi rasa dan pengalaman dengan pelanggan lain. Ini akan menjadi referensi bagi perusahaan yang bersangkutan.

Pelanggan dan produsen samasama diuntungkan dengan terbentuknya kepuasan. Kepuasan akan terjadi kalau perusahaan mampu menyediakan produk, 
pelayanan, harga dan aspek lain sesuai dengan harapan atau melebihi harapan pelanggan. Pelanggan merasa puas apabila harapannya terpenuhi atau akan sangat puas jika harapannya terlampaui. Kepuasan pelanggan dapat didefinisikan sebagai respon pelanggan terhadap ketidaksesuaian antara tingkat kepentingan sebelumnya dan kinerja aktual yang dirasakannya setelah pemakaian (Rangkuty, 2003). Kepuasan adalah perasaan senang atau kecewa seseorang yang muncul setelah membandingkan antara persepsi atau kesannya terhadap kinerja (atau hasil) suatu produk atau jasa dengan harapan-harapannya. Kepuasan merupakan fungsi dari persepsi atau kesan atas kinerja dan harapan.

Banyak perusahaan fokus kepada kepuasan tinggi karena para pelanggan yang kepuasannya tinggi menciptakan kelekatan emosional terhadap merek tertentu, bukan hanya kelekatan atau preferensi rasional. Hasilnya adalah kesetiaan pelanggan yang tinggi (Kotler, 2002).

\section{Loyalitas}

Diintisarikan oleh Hunt dan Arnett (2006) dari berbagai hasil penelitian oleh banyak ahli bidang pemasaran bahwa loyalitas pelanggan dipengaruhi oleh tingkat kepuasan pelanggan. Kemudian pada gilirannya akan membawa laba kepada perusahaan (Zeitham, 1988). Akan tetapi masih ada beberapa kontroversi mengenai keterhubungan antara kepuasan dan loyalitas ini. Hal ini diduga karena masih ada perbedaan pandangan mengenai indikator dan ukuran terhadap loyalitas yang digunakan. Perbedaan ini ditengahi oleh Velazquez et. al (Shirazi \& Som, 2013), dengan dibuatnya kesepakatan untuk mengukur loyalitas yaitu adanya pembelian ulang dan rekomendasi positif dari pelanggan atas produk atau jasa terhadap orang lain. Ditegaskan lagi oleh Chi dan Qu (Shirazi \& Som, 2013), bahwa jika pelanggan puas terhadap suatu produk atau jasa, mereka cenderung untuk terus 
membeli dan menyebarkan hal-hal yang positif terhadap produk dan jasa tersebut kepada orang lain.

\section{Kualitas Layanan}

Zeithaml et.al (Shirazi \& Som, 2013) menyatakan kualitas layanan mengandung aset wujud; tercermin pada fasilitas fisik, peralatan, personil dan bahan komunikasi, keandalan meliputi kemampuan memenuhi layanan yang dijanjikan secara terpercaya, tepat, ketanggapan yaitu kemauan untuk membantu pelanggan dan menyediakan pelayanan yang tepat; jaminan yaitu pengetahuan dari para pegawai dan kemampuan mereka untuk menerima kepercayaan dan kerahasian; dan empati yaitu perhatian individual diberikan oleh perusahaan kepada para pelanggan. Kualitas layanan sangat bergantung pada tiga hal, yaitu sistem, teknologi dan manusia.

Penelitian tentang faktor-faktor yang memengaruhi mahasiswa dalam memilih pemondokan oleh Hajar et. al (2012) dengan menggunakan analisis factor menemukan faktor terpenting adalah lingkungan pemondokan yang bersih. Lingkungan bersih terkait langsung dengan kualitas produk dari pemondokan yang dibangun.

Studi terkait kualitas produk dan kualitas layanan secara simultan dilakukan oleh Devaraj et.al (2001) terkait loyalitas konsumen terhadap industri automotif. Hasil penelitiannya menunjukan bahwa kualitas produk berpengaruh terhadap tingkat loyalitas konsumen dan kualitas layanan berpengaruh terhadap tingkat loyalitas konsumen dengan perantara kepuasan layanan yang dirasakan

Penelitian ini akan mengadopsi model yang digunakan Devaraj (2001). Oleh karena itu hipotesis yang diajukan dalam penelitian ini adalah:

Hipotesis 1: Kualitas produk berpengaruh positif niatan loyalitas dari para penyewa pemondokan Perguruan Tinggi X.

Hipotesis 2: Kualitas layanan berpengaruh positif terhadap kepuasan layanan dari para tenant 
asrama mahasiswa Perguruan

Tinggi $\mathrm{X}$

Hipotesis 3: Kepuasan layanan berpengaruh positif terhadap niatan loyalitas penyewa pemondokan Perguruan Tinggi X

Mengapa digunakan niatan loyalitas bukan loyalitas? Karena belum dapat dipastikan penyewa tersebut loyal atau tidak, dan penelitian ini hanya bisa mengukur nilai niatnya (intention) untuk menjadi loyal atau tidak. Penyewa disebut loyal manakala tetap tinggal di pemondokan sampai dengan menyelesaikan masa studi, dan hal tersebut belum dapat dipastikan untuk saat ini.

\section{METODE PENELITIAN}

Penelitian ini menggunakan metode kuantitatif untuk mendeskripsikan bagaimana pengaruh kualitas layanan dan kualitas produk terhadap kepuasan dan niatan loyalitas (loyalty intention). Subjek penelitian adalah mahasiswa penyewa pemondokan Perguruan Tinggi $\mathrm{X}$ dengan objek penelitian adalah tingkat kepuasan dan niatan loyalitas para penyewa terhadap tingkat kepuasan dan niatan loyalitas. Data diambil dengan menggunakan kuesioner yang diisi secara mandiri (self administered) oleh para responden. Para responden adalah mahasiswa dan mahasiswi yang telah tinggal di asrama selama lebih dari enam bulan. Pembatasan waktu minimal tersebut agar responden dapat menjawab kuesioner sesuai dengan pengalaman yang dirasakan. Enam bulan merupakan waku yang cukup bagi penyewa untuk menilai kualitas layanan dan produk dari pemondokan.

Periode pengambilan data berlangsung selama sepuluh hari terhitung sejak tanggal 1 sampai dengan 11 Februari 2015. Kuesioner disebar dengan cara membagikan ke masing-masing penyewa dan memintanya untuk memasukan lembar kuesioner yang sudah terisi kedalam kotak survey yang telah disediakan. Sebanyak 107 kuesioner berhasil dikumpulkan dan setelah dilakukan pengecekan hanya 105 kuesioner yang pengisiannya memenuhi 
syarat untuk dilakukan analisis

lebih lanjut.

Kuesioner terdiri atas 19 pertanyaan yang mewakili indikator-indikator masing-masing variabel yaitu kualitas produk, kualitas layanan, tingkat kepuasan dan niatan loyalitas. Tabel 1 menyajikan indikator yang digunakan untuk mengukur masingmasing variabel. Ukuran penilaian menggunakan skala likert dari,1 (sangat tidak puas), 2 (tidak puas),
3 (netral), 4 (puas) dan 5 (sangat puas).

Untuk mengukur niatan loyalitas penelitian ini mengadopsi penelitian dari Shirazi (2013) yang mengukur pengaruh pemasaran relasional terhadap loyalitas. Indikator untuk loyalitas yang digunakan adalah, kecenderungan konsumen untuk mengunjungi kembali dan kecenderungan konsumen untuk membeikan rekomendasi.

Tabel 1. Indikator Kualitas Produk dan Kualitas Jasa

\begin{tabular}{|c|c|c|c|}
\hline Kualitas Produk (QP) & $\begin{array}{l}\text { Kualitas } \\
\text { (Servqual) }\end{array}$ & Kepuasan (Sat) & $\begin{array}{l}\text { Loyalty Intention } \\
\text { (Lyt) }\end{array}$ \\
\hline $\begin{array}{ll}\text { - } & \text { Kebersihan (p1) } \\
\text { - } & \text { Tertata rapi (p2) } \\
\text { - } & \text { Berpendingin } \\
& \text { ruangan (p3) } \\
\text { - } & \text { Parkir luas (p4) } \\
\text { - } & \text { Lobby (p5) } \\
\text { - } & \text { Student lounge } \\
& (\mathrm{p} 6) \\
\text { - } & \text { Loundry (p7) } \\
\text { - } & \text { Lokasi (p8) } \\
\text { - } & \text { Biaya transpor } \\
& (\text { p9) } \\
\text { - } & \text { Angkutan umum } \\
& (\mathrm{p} 10) \\
\text { - } & \text { ATM, Kantin } \\
& (\mathrm{p} 11)\end{array}$ & $\begin{array}{ll}\text { - } & \text { Kemampuan } \\
\text { petugas building } \\
\text { management (s1, } \\
\text { s2) } \\
\text { - } \text { Kemampuan } \\
\text { security (s3) } \\
\text { - } \text { Monitoring } \\
\text { supervisor (s4) } \\
\text { - Respon perbaikan } \\
\text { (s5) } \\
\text { - Menanggapi } \\
\text { keluhan (s6) } \\
\text { Sesuai } \\
\text { kemampuan } \\
\text { mahasiswa (s7) } \\
\text { Kemudahan } \\
\text { pelayanan (s8) }\end{array}$ & $\begin{array}{ll}\text { - Nilai } \\
\text { kepuasan } \\
\text { secara } \\
\text { menyeluruh }\end{array}$ & $\begin{array}{ll}\text { - } & \text { Tinggal sampai } \\
\text { - } & \text { Melesai studi (11) } \\
& \text { pada teman (12) }\end{array}$ \\
\hline
\end{tabular}




\section{HASIL DAN PEMBAHASAN}

\section{Profil Responden}

Mayoritas responden yang mengisi dan mengembalikan kuesioner adalah wanita sebanyak 77 orang $(73,3 \%)$ dan pria 25 orang (23,7\%). Didapatkan dua koresponden tidak mengisi pertanyaan untuk jenis kelamin.

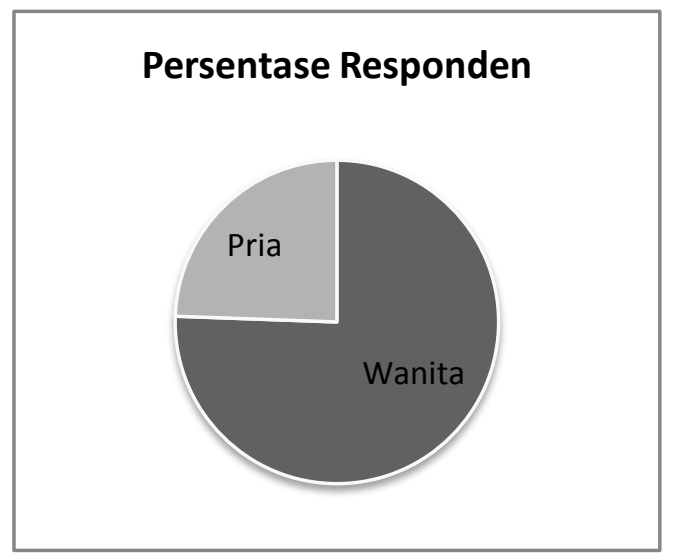

Gambar 1 Proporsi Responden Pria dan Waita

Untuk rentang pengeluaran terbanyak pengeluaran antara 1 juta sampai dengan kurang 2 juta perbulan dengan jumlah 61 orang. Rentang pengeluaran terbesar kedua adalah kurang dari 1 juta perbulan sebanyak 29 orang. Dari daerah asal, terbanyak berasal dari kota Manado sebanyak 12 orang, Bekasi 9 orang, dan Lampung 8 orang.

\section{Uji Validitas Dan Reliabilitas}

Hasil uji validitas yang ditunjukkan pada nilai corected item total corelation menunjukan nilai lebih besar dari 0,195 ( $\mathrm{r}$ tabel a 5\%, $\mathrm{n}=100)$. Dapat disimpulkan bahwa semua indikator yang digunakan dalam penelitian ini sahih (valid)

Hasil Uji Reliabilitas menunjukan bahwa nilai Cronbach's Alpha berada diatas 0,6. Dapat disimpulkan bahwa keseluruh pertanyaan dalam kuesioner memenuhi syarat keandalan.

\section{Uji Asumsi Klasik}

Sebelum dilakukan uji model regresi, dilakukan pengujian untuk melihat apakah sebaran data yang diperoleh memenuhi asumsi klasik.

Uji Normalitas.

Dengan menggunakan uji Kolmogorov-Smirnov Test maka diperoleh nilai K-S sebesar 0,200 > dari nilai 0,05 , sehingga dapat disimpulkan bahwa sebaran data penelitian memenuhi unsur normalitas. 
Uji Heteroskedastisitas

Uji Glejser menunjukkan nilai signifikan lebih besar dari 0,05. Dapat disimpulkan bahwa data yang dikumpulkan telah memenuhi kaidah homogenitas.

\section{Uji Multikolinieritas}

Mencermati nilai VIF untuk masing-masing variabel dibawah 5 dapat disimpulkan bahwa antara masing-masing variabel bebas tidak terjadi korelasi yang kuat (multikolinieritas).

\section{Hasil Uji Model Regresi}

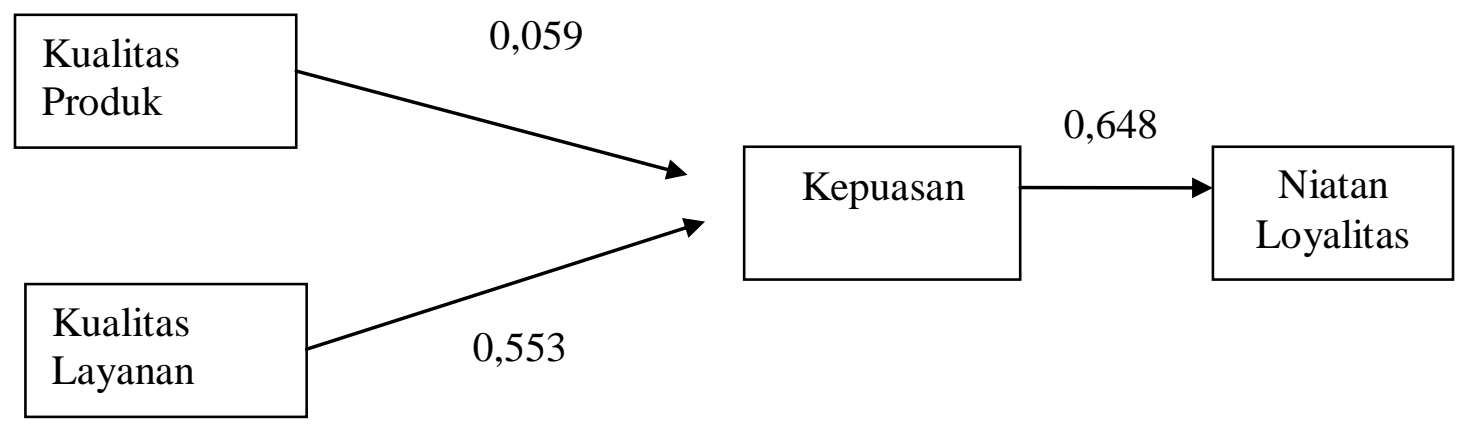

\section{Gambar 2. Hasil Uji Regresi}


Hasil uji regresi menunjukan variabel kualitas layanan berpengaruh signifikan terhadap tingkat kepuasan penyewa. Sementara untuk variabel kualitas produk, tidak memiliki pengaruh yang signifikan terhadap tingkat kepuasan penyewa.

Hasil pengolahan data dengan menggunakan SPSS 22 disajikan dalam tabel berikut ini.

Tabel.2 Hasil Regresi Kualitas Produk dan Kualittas LayananTerhadap Kepuasan

\begin{tabular}{|l|r|c|}
\hline \multicolumn{1}{|c|}{ VAR } & $\begin{array}{r}\text { Standardized } \\
\boldsymbol{\beta}\end{array}$ & $\mathbf{t}$ \\
\hline SAT & $0,648 * * *$ & 8,515 \\
\hline $\begin{array}{l}\mathrm{F}=72,511^{* *} \\
*\end{array}$ & $\mathrm{~N}=101$ & \\
Adj $\mathrm{R}^{2}$ & Dep VAR :Ly & \\
$=0,415$ & & \\
\hline
\end{tabular}

Sumber: Diolah oleh penulis

Hasil pengujian dengan menggunakan 2 variabel bebas kualitas produk (TQP) dan kualitas layanan (T_Servqual) dapat disimpulkan

H1 diterima untuk kualitas layanan, bahwa kualitas layanan berpengaruh positif terhadap tingkat kepuasan dari para penyewa pemondokan mahasiswa Perguruan Tinggi $\mathrm{X}$
H0 tidak ditolak untuk kualitas produk (TQP), Kualitas produk tidak berpengaruh secara signifikan terhadap kepuasan para penyewa pemondokan mahasiswa Perguruan Tinggi X.

Selanjutnya untuk melihat keterhubungan antara tingkat kepuasan terhadap niatan loyalitas dirangkum dalam tabel berikut:

Tabel.3 Hasil Regresi Pengaruh Kepuasan Terhadap Loyalitas

\begin{tabular}{|c|c|c|}
\hline Variabel & $\begin{array}{c}\text { Standardized } \\
\beta \\
\end{array}$ & $\mathbf{t}$ \\
\hline T_Servqual & $0,553 * * *$ & 4,260 \\
\hline TQP & 0,059 & 0,454 \\
\hline $\begin{array}{l}\operatorname{AdjR} R^{2}= \\
0,347\end{array}$ & & \\
\hline $\mathrm{F}=27,522$ & & \\
\hline $\mathrm{N}=100$ & & \\
\hline
\end{tabular}

Sumber: Diolah oleh penulis

Hasil regresi menunjukan $\mathrm{H} 1$ diterima untuk pengaruh kepuasan terhadap niatan loyalitas, bahwa kepuasan layanan yang dirasakan berpengaruh positif terhadap niatan loyalitas para penyewa pemondokan mahasiswa Perguruan Tinggi $\mathrm{X}$.

Kualitas layanan menjadi faktor penting dalam pencapaian 
kepuasan dan loyalitas. Hasil ini berbeda dengan yang penelitian yang dilakukan Aryani dan Rosinta (2010), yang meneliti tentang pengaruh kualitas layanan terhadap keluasan pelanggan restoran cepat saji KFC. Perbedaan ini kemungkinan disebabkan karena ada perbedaan mutlak antara objek penelitian. Dimana KFC adalah gerai penjualan produk sementara pemondokan menawarkan jasa tempat tinggal. Sementara dari karakteristik responden yang dipakai dalam penelitian ini relatif homogen yakni mahasiswa.

Loyalitas suatu perusahaan sangat dipengaruhi oleh cara perusahaan tersebut memuaskan pelanggan. Menurut Schanaars (Aryani \& Rosiinta, 2010) ada empat macam kemungkinan yang terjadi antara kepuasan dengan loyalitas yakni gagal (failures), loyal karena terpaksa (forced loyalty), beralih (defectors) dan sukses (successes). Pada penelitian ini, pemondokan perguruan tinggi $\mathrm{X}$ akan berhasil menjaga loyalitas penyewa jika mempertahankan kepuasan dari para penyewa.

Saat ini, pelanggan lebih sulit terpuaskan karena pelanggan lebih cerdas, lebih sadar harga, lebih menuntut, kurang memaafkan dan didekati oleh banyak pesaing dengan tawaran yang sama atau lebih baik. Tantangannya menurut Kotler (2005), adalah bukan hanya menghasilkan pelanggan yang puas, beberapa pesaing dapat melakukan itu. Tantangannya adalah menghasilkan pelanggan yang senang dan setia

\section{PENUTUP}

Kualitas produk tidak memiliki pengaruh yang signifikan terhadap kepuasan dan niatan loyalitas. Hal ini menunjukan bahwa kepuasan penyewa terhadap jasa pemondokan di perguruan tinggi $X$ hanya semata-mata ditentukan oleh kepuasan yang dirasakan .

Kepuasan merupakan variabel yang akan menentukan kecenderungan terhadap niatan loyalitas dari para penyewa. Semakin tinggi kepuasan yang dirasakan maka niatan loyalitas 
terhadap pemondokan akan ketenangan merupakan fokus utama semakin tinggi. Kepuasan untuk perbaikan kualitas layanan merupakan faktor yang menengahi untuk meningkatkan kepuasan antara kualitas layanan dengan penyewa. Dengan dilakukannya niatan loyalitas. Tanpa memperoleh peningkatan kualitas layanan akan rasa kepuasan niatan untuk loyalitas akan semakin menurun.

meningkatkan kepuasan penyewa sehingga akan menimbulkan niatan Kepuasan para penyewa semata-mata hanya dipenuhi oleh kualitas layanan. Ketatnya persaingan bisnis pemondokan menuntut penyedia jasa tidak hanya menyajikan kualitas produk yang bagus, namun juga harus diikuti oleh kualitas layanan yang prima.

Kecepatan menanggapi keluhan penyewa, kenyamanan selama berada di lokasi asrama dan loyalitas.

Penelitian ini baru meninjau kepuasan secara umum dengan menggunakan kualitas produk dan kualitas jasa. Penelitian selanjutnya diharapkan dapat menambah variabel-variabel yang diduga berpengaruh terhadap tingkat kepuasan penyewa dengan melibatkan responden yang lebih banyak dan beragam.

\section{DAFTAR PUSTAKA}

Devaraj, S., Matta, K., \& Conlin, E. (2001). Product and Service Quality : The Antecedents of Customer Loyalty In The Automotive Industri. Production and Operation Management, Vol.10 No. 4 , 424.

Hajar, S. M. (2012). Faktor-Faktor yang Memengaruhi Manusia Dalam Memilih Rumah Kos. e-Journal Matematika Vol.1 No.1 , 25-31.

Hunt, S. . (2006). The explanatory foundations of relationship marketing theory Volume 21 • Number 2 • 2006 • 72-87. Journal of Business \& Industrial Marketing , 72-87.

Irawan, H. (2008). Sepuluh Prinsip Kepuasan Pelanggan. Jakarta: Elex Media Komputindo Kelompok Gramedia. 
Kotler, P. (2002). Manajemen Pemasaran. Edisi Miilenium Satu.. Jakarta: Prenhalindo.

Rangkuty, F. (2003). Measuring Customer Satisfaction. Jakarta: Penerbit GramediaPustaka Utama .

Shirazi, F. M., \& Som, A. P. (2013). Relationship Marketing and Destination Loyalty : Evidence From Penang Malaysia. International Journal of Management and Marketing Research, Vol. 6, 95-106.

Zeitham, V. (1988). Consumer Perception of Price, Quality and Value; A Means-End Model and Synthesis of Evidence. Journal of Marketing , $52,3,2-22$. 